\title{
ORIENTADOR OU TUTOR É AUTOR?
}

\section{ORIENTADOR, TUTOR O DIRECTOR DE TESIS, ¿ES AUTOR?}

\author{
Maria das Graças Targino - gracatargino@hotmail.com \\ Doutora em Ciência da Informação e Pós-Doutora em Jornalismo \\ Professora Colaboradora do Programa de Pós-Graduação em Ciência da \\ Informação, \\ Universidade Federal da Paraíba, UFPB
}

\begin{abstract}
Resumo
Ao decorrer dos tempos, as profundas mudanças no ensino e na pesquisa advindas do avanço tecnológico e, sobretudo, a valoração crescente do ensino superior e da investigação científica vêm acarretando intensa controvérsia em torno do velho e desgastado slogan publish or perish. Cada vez mais, orientadores ou tutores de teses e trabalhos acadêmicos em geral aparecem como primeiro autor ou co-autor de trabalhos realizados por seus alunos, recorrendo ao argumento de que a autoria, como atividade e processo, sofre intensas mutações sociais, culturais, econômicas e políticas. Este é um tema que suscita debate e conduz a mudanças conceituais que exigem a reconstrução dos fundamentos teóricos que cercam a autoria, mas sem relegar a questão ética de respeito à produção do outro.
\end{abstract}

\section{Palavras-chave}

Autoria. Co-autoria. Orientação. Trabalhos acadêmicos. Monografias acadêmicas. Teses.

\section{INTRODUÇÃO: NOVOS TEMPOS PARA A PESQUISA E A PRODUÇÃO CIENTÍFICA}

No Brasil e fora dele, nos mais diferentes países, mais e mais, discute-se o processo autoral, diante das profundas mudanças ocorridas no ensino, como também na execução de pesquisas científicas. São transmutações advindas do avanço significativo das tecnologias de informação e de comunicação (TIC), e, também, da pressão crescente para que acadêmicos e pesquisadores produzam mais e mais e se insiram em grupos de pesquisa. Isto porque, há tendência progressiva para que as agências de pesquisa, internacionais ou nacionais, valorizem os esforços em equipe muito mais do que os trabalhos individuais. 
Como decorrência, há inquestionável alteração na configuração da comunidade científica contemporânea, embora sua concepção continue em vigor. Ainda hoje, tal como Thomas S. Kuhn defende, em sua obra clássica, The structure of scientific revolutions, originalmente do ano 62 , a comunidade científica consiste em homens que partilham de um paradigma ou, inversamente, um paradigma é aquilo que os membros de uma comunidade partilham. Em outras palavras, a expressão em pauta designa não somente a totalidade dos indivíduos que se dedicam à pesquisa científica e tecnológica como também grupos específicos de cientistas, segmentados em função de suas especialidades e / ou de línguas, nações e ideologias políticas. Os partícipes de uma comunidade científica possuem interesse em torno de uma especialidade. Como resultado, são eles os responsáveis pela consecução de objetivos comuns, o que reforça certo nível de agregação e união, observando-se que, no interior desses grupos, em geral, a comunicação é satisfatória e os julgamentos profissionais quase sempre unânimes, embora não estejam livres de conflitos e de disputas internas.

Em sua análise da história da ciência e na utilização e popularização do termo paradigma, Kuhn (1970) insiste que as comunidades científicas existem em vários níveis, uma vez que as grandes áreas, invariavelmente, se desdobram em subáreas ou especialidades. Por exemplo, o amplo universo da comunicação social, na realidade brasileira, incorpora jornalismo, relações públicas, publicidade e propaganda, produção editorial, radialismo (rádio e televisão) e cinema. Sob esta perspectiva, ao contrário do previsto por Le Coadic (1996), para quem, a noção de comunidade científica é ambígua e se relaciona com o mito, surgido no século XIX, alusivo à "república das idéias" ou à "cidade do saber", onde cientistas se encontravam para trocar idéias abstratas em busca da verdade, hoje, na sociedade contemporânea, essas comunidades nada têm de abstração. Ao contrário, possuem aspirações bem definidas, em que há efetivo sistema de trocas. O pesquisador repassa à "sua" coletividade informações que detém e os conhecimentos recém-gerados. Em troca, recebe sua confirmação como cientista. Esta se dá em dois estágios. De início, o reconhecimento dos pares. Posteriormente, confirmação institucional mediante produção intensa de publicações originais.

Os membros da comunidade científica mantêm vinculação profissional com instituições distintas, incluindo, no caso do Brasil, majoritariamente, universidades e institutos de pesquisa, além de academias, sociedades científicas e associações de pesquisadores. Para Le Coadic, essa institucionalização acontece em cinco etapas, não necessariamente excludentes. A primeira tem como representante máximo o cientista isolado, sem amparo institucional, mas com garra e obstinação, dando margem ao estereótipo do "cientista maluco, solitário e excêntrico". Num segundo momento, esforços avulsos dão origem às primeiras tentativas de trabalho coletivo, em torno de um pesquisador-líder - é o amadorismo científico. A terceira etapa é marcada pela expansão das universidades como academias do saber, configurando a ciência acadêmica. A ciência organizada, estágio que prevalece na atualidade, favorece os alicerces de programas, sobretudo oficiais, com vistas ao avanço da pesquisa. A última etapa - megaciência - refere-se ao reconhecido valor dos pesquisadores envolvidos, em esfera nacional e internacional, atuando em laboratórios com equipamentos de última geração e contando com recursos financeiros satisfatórios. 
Decerto, tudo isto, junto com a evolução das TIC, constitui um conjunto essencial de elementos para o entendimento das mudanças que rondam a autoria e a co-autoria. Diante do surrado e sempre discutível lema publish o perish, cada vez mais, há dúvidas no momento de se atribuir autoria a determinado texto, em especial, no caso dos que provêem de estudos realizados na pós-graduação. Nesta etapa, a figura do orientador e / ou do co-orientador (um segundo professor que complementa / auxilia a orientação) é imprescindível, em termos formais / legais e, sobretudo, no apoio aos iniciantes, os quais, com raras exceções, carecem de maturidade intelectual. Diante da pressuposição de que não existem respostas únicas ou unívocas, mas que é preciso primar, sempre, por postura ética na inter-relação orientador versus (vs.) orientando no contexto da produção intelectual, e, por conseguinte, na formação intelectual e integral dos indivíduos, fundamentamos nossa discussão nas concepções mais clássicas de autoria e coautoria e de orientação.

\section{AUTORIA E CO-AUTORIA: NOVOS TEMPOS E NOVAS DÚVIDAS}

A princípio, retomamos um dos conceitos mais completos sobre autoria, apresentado por Culliton, ainda em 1994. Para ele, só é autor quem, de fato, participa e assume de forma integral a responsabilidade da produção do texto, qualquer que seja sua natureza. Autor e co-autores necessitam participar, efetivamente, de todas as fases de produção, haja vista que se o trabalho resulta de esforço conjunto, a diferença entre autor e co-autor se limita à liderança maior ou menor no encaminhamento das atividades e não na responsabilidade autoral. Autor e co-autores devem colaborar em todas as etapas. Estas compreendem a concepção da idéia, a delimitação do objeto de estudo, a consecução dos objetivos pretendidos, além do estabelecimento da linha teórica adotada. Abrangem, ainda, a decisão dos procedimentos metodológicos, análise e respectiva interpretação dos dados coletados até a elaboração preliminar e final do texto que sumariza resultados e conclusões obtidas.

No entanto, a denominada explosão bibliográfica, resultante de fatores variados (incremento da pesquisa, do total de pesquisadores e de sua produtividade; avanço das nações; compartimentação da ciência e tecnologia, C\&T; industrialização acelerada; especialização crescente; impressão rápida; TIC em expansão, etc.), além de possibilitar a qualquer indivíduo tornar-se autor, quase de imediato, concorre para a intensificação do fluxo informacional e, pior, para a banalização da autoria. Isto é, maior chance de publicar corresponde a mais informações em circulação. Mais informações em circulação, por sua vez, corresponde a mais problemas em torno do processo de autoria, independentemente do suporte impresso ou eletrônico.

Assim, debates sobre a "morte do autor" ganham espaço e delineiam duas grandes correntes de pensamento. Enquanto há quem decrete o fim da autoria, há quem se oponha terminantemente a esta pressuposição. Ora, a história da autoria, descrita por estudiosos de especialidades e nacionalidades distintas, como Roland Barthes (2008); Ítalo Calvino (2000); Michel Foucault (1992); e Jack Meadows (1999), aponta mudanças de natureza social, cultural, econômica e política, que acompanham a atividade do autor no decorrer dos anos. Sem negar a intertextualidade ou a polifonia dos textos de distintas naturezas, os estudiosos 
acordam que os textos acionam, irremediavelmente, outras vozes ou outros textos.

Porém, ao contrário do que Kucinski (2005) apregoa, mudanças autorais profundas, em nenhuma perspectiva, podem ser vistas como sinônimo de "morte" da autoria. Ao tempo em que qualquer obra é sempre uma obra aberta (ECO, 1979), ao permitir leituras variadas e formas múltiplas de interação texto-leitor, o autor não apenas sobrevive, mas persiste com força total:

Não há obra sem autor. O desconhecimento do autor não implica sua inexistência. O maior ou menor grau de participação na criação de uma obra não invalida a sua intervenção.Pretender assimilar a função de um autor à de um leitor-autor não invalida a existência de um autor [...] (OTTOBRE, 2005, p. 43).

Em se tratando do avanço das TIC ou, em especial, da internet e das publicações eletrônicas, para Foucault (1992), o texto é capturado num sistema de referências com outros textos postos na Grande Rede, onde há infinitos espaços e "mundos impossíveis". Esta intervenção torna o acesso à informação rápido e abrangente, ao tempo em que transmuta o leitor em construtor de sentidos, reduzindo a autonomia dos textos e dos próprios autores. Os discursos, indo além dos limites da língua, estão atrelados às suas determinações. Portanto, somente podem ser definidos como prática social e / ou prática discursiva, na concepção de sistema que, no interior de determinada formação discursiva, regula a dispersão dos lugares institucionais passíveis de serem ocupados por um sujeito de enunciação. Quer dizer, face à posição privilegiada do hipertexto, mais do que antes, ocorre visível entrelaçamento entre as funções de autor e as de leitor.

Os hipertextos dão poder de comando aos leitores para que tracem caminhos individualizados e construam metatextos variados e imprevisíveis, originados de interconexões com outros documentos do mesmo autor ou de vários outros, num sistema de referências sem limites. Além de amplificar as chances de informações, para Barthes (2008), o hipertexto e os "passeios" que proporciona, reduz a autonomia dos textos, e, portanto, dos próprios autores. Trata-se de idéia que, indiretamente, referenda Foucault (1992), para quem os autores não são apenas autores das obras que levam sua assinatura, mas produzem, essencialmente, a chance de constituição de outros textos, estabelecendo a possibilidade indefinida e infinita de discursos.

Na mesma linha de pensamento, e tal como Umberto Eco, Salvador Pocho Ottobre evidencia que todos somos leitores-autores. De alguma forma, completamos a mensagem original em nossa mente, de forma mais sólida ou não, de forma mais fiel ou não, de forma mais inovadora ou não, e assim sucessivamente. Mas, sempre o fazemos. A idéia do leitor-autor está vinculada ao imaginário de cada um: "[...] o 'leitor-autor' decidirá o tipo de vida que quer para suas personagens, criará personagens novas, transformará a história" (OTTOBRE, 2005, p. 26), o que justifica a expressão leitor-ator, a partir da acepção de ator [do latim actore], como "agente do ato". 
Neste processo de mudanças, a discussão sobre autoria / co-autoria se impõe como realidade aliada à valorização da informação como fonte de poder e à conseqüente pressão exacerbada, pelo mundo afora, para que se publique mais e mais, em adesão ao decantado lema anglo-saxônico publish or perish. A ênfase na produção científica possui vantagens: ao contrário dos matemáticos e alquimistas do Renascimento, hoje, os cientistas revelam os resultados de seu trabalho de imediato. No entanto, as desvantagens existem: condicionados à coação social e profissional para que produzam quase compulsivamente, em meio a um sistema de avaliação de desempenho calcado, sobremaneira, na produção quantitativa, e indiferente às distinções entre instituições, áreas, subáreas, temas e objetos de estudo, acadêmicos e pesquisadores tendem a participar de verdadeira "indústria da pesquisa de papéis". A investigação científica substitui seu objetivo máximo - avanço da C\&T - pela produção meramente quantitativa de artigos e papers, cuja intenção primordial é assegurar ascensão profissional, conceitos mais elevados para os Programas de PósGraduação e / ou concessão de benefícios (TARGINO, 2005).

Fiéis à caracterização da indústria como atividade de produção de mercadorias, de forma mecanizada e em grande escala, os acadêmicos, como partícipes da tal indústria, substituem, de forma frenética, a autoria individual pela co-autoria / autoria coletiva / autoria múltipla / autoria compartilhada. Mais do que ultrapassar a etapa do "cientista solitário" ou de superar a equivocada autoria individual como identidade formalizada do autor em pretensa objetividade, perfazendo o binômio autor $\mathrm{x}$ obra e / ou sujeito $\mathrm{x}$ objeto, os passos desses pesquisadores os levam ao outro extremo.

Em lugar da co-autoria fiel aos contratos éticos, sociais e jurídicos pertinentes, e em sintonia com o Estado e com as exigências mercadológicas (ANTONIO, 2010), os desatinos se acentuam. Agora, ao nome do autor verdadeiro, acrescenta-se, por coação, amizade, conveniência, falta de esclarecimento, intenção de facilitar a ascensão funcional do colega etc., o nome de pseudocolaboradores, em atitude aética, vez que autor / co-autor é tãosomente quem participa de todas as etapas do trabalho intelectual, como antes assinalado. Há, ainda, mais dois fatores agravantes, que tendem a se expandir pelos países afora. Primeiro, a exigência radical dos órgãos de fomento de priorizar projetos integrados de pesquisa, sob a ótica de institucionalização da ciência prevista por Le Coadic (1996), visando à chamada ciência organizada. Segundo, as revistas renomadas e os eventos técnico-científicos, em geral, salvo raras exceções, privilegiam textos produzidos por autores com titulações mais elevadas, como forma de atender aos requisitos impostos por agências de fomento.

Sem dúvida, todos estes fatores são determinantes para a prática de inclusão do nome dos orientadores ou tutores aos textos dos alunos. De forma crescente, se colocam como primeiro autor ou co-autor de trabalhos elaborados por seus alunos. Argumentam que sua atitude resulta das mudanças sofridas pela autoria, no decorrer das décadas. Julgam ser esta a forma ideal de assegurar publicação ou de imprimir aos textos maior credibilidade. E, decerto, são estas tendências (equivocadas ou não) que estão incentivando a que se estabeleçam parâmetros para definição de níveis / ordenação de autoria, a exemplo de tabela 
idealizada por Petroianu (2005), para a área médica, ainda que distantes do conceito clássico de autoria, defendida por Cullinton (1994) e Ottobre (2005).

Assim, de novo, enfrentamos situação de dupla face. A postura das agências de financiamento e das revistas favorece a conjunção de esforços de pesquisadores juniores e seniores. Do outro lado, porém, estimula maiores enganos no processo autoral, em desobediência às prescrições éticas no campo da pesquisa científica, descritas, em detalhes, por Witter (2010, p. 10, grifos nossos), e aplicáveis, conseqüentemente, à comunicação científica / produção científica:

\begin{abstract}
A ética na pesquisa é um aprendizado que deve estar associado ao saber-fazer-poder da ciência desde a pré-escola até a pósgraduação, esperando-se que os profissionais que usam e que produzem conhecimento científico incluam em seu plano de atualização permanente o aprimoramento constante sobre ética em ciências.
\end{abstract}

Embora o principal responsável pela ética científica seja o pesquisador há outras pessoas envolvidas como participantes ou sujeitos, financiadores (públicos ou privados), difusores da ciência (meios de comunicação de massa e meios científicos), gestores e consumidores ou usuários da ciência.

Quer dizer, as tendências atuais de inclusão de orientadores ou de mais profissionais como autores, ainda que discutíveis, parecem estar em sintonia com - Estado (estatísticas oficiais das instituições de ensino superior, IES e dos institutos de pesquisa) e com as novas demandas do mercado, que se fortalecem, num crescendo editorial sem limites. Coletâneas de todos os tipos e sem fio condutor são lançadas. Revistas surgem e morrem com rapidez incrível. Um mesmo trabalho gera vários "filhos", legítimos ou ilegítimos. Papers de poucas laudas, apresentados em congressos ou publicados em revistas, contam com número inacreditável de co-autores, com a presença inevitável de orientadores vs. orientandos.

Os exemplos estão à vista de qualquer um. Há de tudo. Tudo é permitido e incentivado por posições, como as de Kucinski (2005), para quem o plágio tende a ser universalizado diante dos novos hábitos que avançam no espaço virtual, incluindo venda de trabalhos e de publicações escritas a várias mãos, que excitam a curiosidade e a criatividade, mas não podem ser elevadas a postos máximos. Exemplificando: a Britannica Online cede espaço à Wikipedia, enciclopédia livre e eletrônica, mas cuja credibilidade é contestada por Keen (2009), que mostra, com argumentos sólidos, a fragilidade de parte de seus conteúdos, provenientes de fontes duvidosas, e, muitas vezes, anônimas.

\title{
3 ORIENTAÇÃO: NOVOS TEMPOS E NOVA POSTURA
}

Como antes citado, por conta da pressão social e profissional para que se publique, a orientação ou a co-orientação assume função vital, desde a 
graduação, com ênfase para a pós-graduação. Há exigência formal, por parte das IES. Há exigência implícita, diante da necessidade de favorecer ao aluno acompanhamento sistemático de sua aprendizagem, mediante a utilização de técnicas, recursos e procedimentos adequados aos objetos de estudo.

Neste sentido, o orientador deve ser essencialmente um educador dotado de certos pré-requisitos. Dentre eles: ter experiência no campo da pesquisa científica, e, portanto, titulação ou formação elevada (doutorado ou pósdoutorado); ser professor de tempo integral e dedicação exclusiva. No plano comportamental, os orientadores mantêm formas de atuação diversificadas, ou seja, por persuasão ou por índole, variam em seus estilos de trabalho, como especificado pelo economista e educador Cláudio de Moura Castro há mais de duas décadas, e ainda válido para a atualidade:

Uns são pacientes, outros afoitos; uns são benevolentes, outros zangados. Alguns vetam sucessivamente até que os alunos consigam chegar finalmente por conta própria à solução correta. Outros quase chegam a fazer o trabalho do aluno. Naturalmente, alguns têm mais tempo ou mais disposição para gastá-lo com seus alunos (CASTRO, 1978, p. 326).

Em qualquer circunstância, porém, o orientador precisa perceber 0 orientando em sua integridade, levando em conta as três faces componentes de uma personalidade - racional, afetiva e emotiva -, a fim de estabelecer parceria fundamentada na confiança e no respeito mútuos, dentro dos limites fixados pelo bom senso. Além do domínio da temática, com freqüência, exerce papéis distintos, como o de professor de português e de estatística, bibliotecário, além de psicólogo, para lidar com questões do domínio afetivo. Afinal, para quase todos os pesquisadores juniores, a fase de iniciação no universo da pesquisa e da produção intelectual representa um período de tensão, expectativas e temor. Reforça-se o mito do "bicho de sete cabeças" e certo misticismo, de que é essencial devoção, renúncia e contemplação, para se alcançar o estado extático da conclusão dos trabalhos de pesquisa.

Ademais, compete ao orientador propor e dinamizar linhas de pesquisa, além de analisar a viabilidade e a importância dos temas propostos pelos discentes, numa visão contextual nacional, regional e local. Também é figura decisiva para, diante da dificuldade crescente de se pesquisar em campos "virgens", buscar com o aluno novas formas de abordagem e facetas inovadoras, que atinjam soluções criativas e originais, favorecendo o estudo de fatos e fenômenos. Sobre este item, Tyler (1994) reforça que orientar pressupõe conhecer uma teoria, um volume de conceitos concatenados acerca da vida, da natureza humana e de métodos capazes de sistematizar os conhecimentos em produtos úteis às coletividades.

Portanto, em termos ideais, tanto para o autor supracitado como para Castro (1978), o orientador deve seguir alguns parâmetros essenciais: (a) planejamento prévio quanto à sistemática da orientação, incluindo horários, duração das entrevistas, cronograma de tarefas e demais detalhes; (b) estímulo a discussões técnico-científicas, evitando interferências subjetivas; (c) apoio a possíveis divergências de opinião, uma vez que ao orientador não compete 
doutrinar ou catequizar; (d) ênfase à responsabilidade do aluno, como genuíno autor de seus trabalhos.

Este último item resume a essência da discussão. Ao orientador compete acompanhar, segundo técnicas específicas, o desenvolvimento intelectual e a formação integral do aluno, mas este é o autor de seus próprios textos, desde o momento que deve assumir responsabilidade incondicional por sua elaboração, publicação e divulgação, como Culliton (1994) chama a atenção. Sob tal ótica, os novos tempos de maior pressão para publicar e a ameaça de enviar ao limbo os acadêmicos que publicam menos (o que requer discussão intensa e profunda sobre o elemento qualitativo vs. quantitativo), não justifica a tendência ora acentuada de o orientador se posicionar como autor ou co-autor dos trabalhos de seus alunos.

\section{AUTORIA E ORIENTAÇÃO: UNIVERSOS QUE SE CRUZAM}

Logo, conscientes da impossibilidade de posições conclusivas, reiteramos nossa crença de que orientadores ou tutores podem, sim, figurar como autores, como qualquer outro intelectual. Porém, não podem ou não devem constar como autor ou co-autor da produção principal de seus orientandos (trabalhos de conclusão de curso, dissertações e teses), o que não impede que mais adiante produzam efetivamente juntos, em igualdade de condições. Trata-se de inferência amparada numa proposta de produção científica pautada pela ética que deve existir na comunidade científica, distante da aceitação passiva da produtividade como sinônimo da "indústria da pesquisa de papéis", e, sobretudo, fundamentadas, nas concepções antes exploradas do que é autoria e do que é orientação.

A partir do momento que percebemos as funções diferenciadas do autor $\mathrm{e}$ do orientador, parece mais fácil, ou, no mínimo, menos polêmico, a compreensão de que são universos que se cruzam, mas que mantêm sua singularidade. Orientar, estabelecer diretrizes, intercambiar experiências são atividades intrínsecas à orientação e não à autoria. Orientadores e autores, professores e alunos podem ser membros integrantes da comunidade científica, em termos efetivos ou em potencial, mas sem que o espaço de um seja usurpado pelo outro.

Além disto, reiteramos que a profissionalização da pesquisa, prevista por Le Coadic (1996) e Meadows (1999), traz subjacente a inclusão de remuneração. Nos dias de hoje, a produção científica, além de confirmar competência, pode assegurar empregos, e quiçá, prêmios e recompensas. Isto é, a ampliação dos meios até então utilizados na comunicação científica acrescenta à regulamentação de natureza intelectual da comunidade científica uma regulamentação de natureza econômica. O número crescente de pesquisadores provoca a estratificação interna da pesquisa. Resultante da interferência de tais fatores, as comunidades científicas apresentam, hoje, divisão de trabalho bem mais complexa com atribuição de tarefas delimitada, centralização de autoridade mais visível, gerenciamento do processo de execução da pesquisa e monitoramento de informações.

Neste sentido, o orientador não deve reforçar sua autoridade desrespeitando a concepção da autoria em seus fundamentos precípuos, o que 
acarreta graves conseqüências para os direitos morais e patrimoniais presentes na atuação profissional do autor. Retomando Foucault (1992), pode-se argumentar que a função-autor não nos remete tão-somente a um indivíduo real e, sim, dá lugar a diferentes "eus", simultaneamente. A função-autor efetua-se na própria cisão - mesma divisão e uma divisão -, o que justificaria possível fusão da produção do orientando com a do orientador. Mesmo assim, reiteramos que a comunidade científica constitui espaço de troca, em que os pesquisadores, sejam juniores ou seniores, sonham com sua aceitação no âmago da comunidade a que pertence e à sociedade em geral, no momento em que disponibilizam os resultados de sua pesquisa. Se aos juniores não se der oportunidade igualitária, seu caminho em direção ao reconhecimento pelos pares e a subseqüente confirmação institucional tardará ou não se efetivará, contrariando frontalmente as denominadas normas mertonianas, publicadas ainda em 1937, e que estão em voga até hoje, pleno século XXI.

Dentre as quatro normas de R. Merton - universalidade; compartilhamento; desapego material e ceticismo sistemático - a posse da produção do orientando pelo orientador fere, no mínimo, a duas delas (TARGINO, 2005). Primeiro, a universalidade, que veta a existência de qualquer fonte privilegiada do saber científico. Quer dizer, toda e qualquer contribuição científica deve ser avaliada mediante critérios rigorosos, objetivos e impessoais. Sua aceitação ou rejeição independe dos atributos individuais ou sociais do autor, de tal forma que titulação, renome ou outros atributos do indivíduo deveriam ser irrelevantes. É evidente, então, que as prescrições, explícitas ou implícitas, adotadas tanto pelas agências de fomento como pelas grandes revistas, não cumprem a universalidade idealizada pelos defensores de uma ciência menos impregnada de interesses particulares e institucionais.

De forma similar, a aposição do nome do orientador / co-orientador ao texto do aluno contraria o ceticismo sistemático. De acordo com tal recomendação, os pesquisadores não podem aceitar nada de boa fé. Devem verificar, sempre, os novos conhecimentos, em busca de erros, inconsistências e fragilidades, num comportamento radicalmente cético e paradoxalmente producente, uma vez que visa à verossimilitude dos resultados das pesquisas recém-publicadas.

Por tudo isto, acreditamos que admitir orientador / co-orientador como autor ou co-autor da produção do orientando corresponde à aceitação e ao reforço do decantado e criticado argumento de autoridade na ciência. Este diz respeito à predisposição de se aceitar como verdadeiras o enunciado por pessoas de prestígio, e que contribui para que os avaliadores, nas mais diferentes instâncias - órgãos governamentais ou não, publicações, eventos, etc. - acatem, sem muito rigor, as contribuições advindas dos "medalhões", enquanto os papers oriundos de pesquisadores iniciantes ou vinculados a instituições de pequeno porte são metricamente analisados e dissecados. Aqui, é interessante observar a postura do próprio Meadows (1999), autor clássico da comunicação científica. Afirma, literalmente (p. 60): "Editores estão sempre ansiosos para garantir que os artigos sejam aceitos por seu mérito, e não porque seu autor tem renome". Mais adiante, porém, cita o caso dos membros da National Academy of Sciences que publicam trabalhos nos proceedings da Academia após revisão pro forma. Acredita-se que seus membros, como autores experientes (leia-se, famosos) têm consciência do que é um artigo aceitável, o que representa negação da imparcialidade. 
Por fim, diante das profundas transformações que afetam o homem contemporâneo, em termos profissionais e pessoais, determinando, às vezes, total inversão de valores, é ingenuidade pensar, como Foucault (1992) alerta, que a função-autor pode permanecer inalterada ou imune, em sua forma, complexidade e existência. Por outro lado, constitui temeridade aderir à autoria coletiva, sem atentar para a concepção básica da autoria e os ditames éticos a ela inerentes, tornando-se fabricante de uma ciência comprometida com a centralização da autoridade e com o exercício do poder... Há que cuidar para não cometermos arbitrariedades em nome de uma falsa modernidade...

\section{REFERÊNCIAS}

ANTONIO, I. Autoria y cultura posmoderna. 2010. Disponível em: <http://bvs.sld.cu/ revistas/aci>. Acesso em: 8 nov. 2010.

BARTHES, R. O rumor da língua. São Paulo: Brasiliense, 2008.

CALVINO, I. Seis propostas para o próximo milênio. Petrópolis, RJ: Vozes, 2000.

CASTRO, C. M., Memórias de um orientador de tese. In: NUNES, E. de O.

(Coord.). A aventura sociológica. Rio de Janeiro: Zahar, 1978. p. 307-326.

CULLITON, B. J. Integrity of research papers questioned. Science, Washington, DC, v. 235, p. 422.423, Jan. 1994.

ECO, U. Obra abierta. Barcelona: Ariel, 1979.

FOUCAULT, M. O que é um autor? Vega: Passagens, 1992.

KEEN, A. O culto do amador: como blogs, MySpace; YouTube e a pirataria digital estão destruindo nossa economia, cultura e valores. Rio de Janeiro: Zahar, 2009.

KUCINSKI, B. Jornalismo na era virtual. São Paulo: Fundação Perseu Abramo, 2005.

KUHN, T. S. The structure of scientific revolutions. Chicago: University of Chicago, 1970.

LE COADIC, Y.-F. La science de l'information. Paris, Presses Universitaires de France, 1996.

MEADOWS, A. J. A comunicação científica. Brasília, DF: Briquet Lemos Livros, 1999.

OTTOBRE, S. P. Elogio del autor. Buenos Aires: La Crujía, 2005.

PETROIANU, A. Autoria de um trabalho científico. Revista da Associação Médica Brasileira, São Paulo, v. 8, n. 1, p. 60-65, 2005. 
TARGINO, M. das G. Artigos científicos: a saga da autoria e co-autoria. In: FERREIRA, S. M. S. P.; TARGINO, M. das G. (Org.). Preparação de revistas científicas: teoria e prática. São Paulo: Reichmann \& Autores Ed., 2005. p. 35-54.

TYLER, L. E. La función del orientador. México: Trillas, 1994.

WITTER, G. P. Ética e pesquisa: gestores e pesquisadores. In: CURTY, R. (Org.). Produção intelectual no ambiente acadêmico. Londrina: Departamento de Ciência da Informação, Universidade Estadual de Londrina, 2010. p. 9-29.

\section{Title}

\section{Mentors or directors of thesis, is he author?}

Over time, with the profound changes in the learning and in research provided by technological advances, and especially because of the extreme value of higher education and scientific research, there is an intense discussion around the old and worn slogan "publish or perish. " Increasingly, mentors or directors of thesis and university papers, en general, put themselves as first author or coauthor of work performed by their students, by the argument that the author, as activity and process, suffers herself social, cultural, economic and political mutations. This is a topic that arouses controversy and leads to conceptual changes, which require the deconstruction of its foundations, which, however, must respect the ethic behavior.

\section{Keywords}

Authorship. Co-Authorship. Supervisor. Academic Theses and Monographs.

\section{Título}

Orientador, tutor o director de tesis, ¿es autor?

\section{Resumen}

A lo largo del tiempo, con los profundos cambios en la enseñanza e investigación provenientes de los avances tecnológicos, y sobre todo por el valor creciente de la educación superior y de la investigación científica, hay intensas controversias alrededor del viejo y gastado lema "publicar o morir". Cada vez más, tutores o directores de tesis y monografías académicas en general, se colocan como primer autor o coautor de los trabajos realizados por sus alumnos, utilizando el argumento de que la autoría, como actividad y proceso, sufre ella misma intensas mutaciones sociales, culturales, económicas y políticas. Este es un tema que despierta discusiones y conduce a cambios conceptuales que requieren la reconstrucción de sus fundamentos, aunque respecto por la cuestión ética debe tenerse en cuenta.

Palabras clave: Autoría, Coautoría, Tutoría, Tesis y Monografías Académicas. 
Recebido em: 10/11/2010

Aceito em: 12/12/2010 